Key words: thin-walled structures, composite, FEM, coupling, vibration, eigenvalue problem, experimental method

\title{
MODAL ANALYSIS OF LAMINATED “CAS” AND “CUS” BOX-BEAMS
}

\begin{abstract}
In the paper, the authors discuss the numerical and experimental modal analysis of the cantilever thin-walled beams made of a carbon-epoxy laminate. Two types of beams were considered: circumferentially asymmetric stiffness (i.e., CAS) and circumferentially uniform stiffness (i.e., CUS) beams. The layer-up configurations of the laminate were chosen to get a vibration mode coupling effect in both analysed cases. The aim of the paper was to perform the numerical and experimental modal analysis of the composite structures, when a flapwise bending with torsion coupling effect or flapwise-chordwise bending coupling effect took place. Firstly, numerical studies by the finite element method was performed. The numerical simulations were carried out by the Lanczos method in the Abaqus software package. The natural frequencies and the corresponding free vibration modes were determined. Next, the experimental modal analyses of the CAS and CUS beams were performed. The test stand was consisted of a special grip, two beams with an adhered holder, the LMS Scadas III system with a modal hammer and an acceleration sensor. Finally, the results of both methods were compared.
\end{abstract}

\section{Introduction}

Vibration analysis of thin-walled structures made of a modern laminates is a very important topic in contemporary mechanics. The configuration of the laminate layer system can change the mechanical properties of the structure and thus its dynamic behaviour. In addition, there are many interesting effects unmatched for thin-walled structures made of isotropic material. The coupling effect between different vibration modes is particularly interesting. The flapwise bending-torsion or flapwise-chordwise bending vibrations coupling effects can be observed for the

\footnotetext{
${ }^{1}$ Department of Applied Mechanics, Mechanical Engineering Faculty, Lublin University of Technology, Nadbystrzycka 36,20-618 Lublin, Poland. Emails: j.gawryluk@pollub.pl, m.bochenski@pollub.pl,a.teter@pollub.pl
} 
thin-walled laminated beams. The theory of the thin-walled beams was developed in the papers by Librescu and Song [1-4]. There are presented many analytical solutions for the vibrations occurring in this type of structures. Song and Librescu [4] discussed a bending vibration problem of the thin-walled laminated beam subjected to a harmonic load. Dynamic response of the thin-walled beams with closed cross-sections when a flexure-torsion coupled effect took place under random load was presented in paper [5]. Kaya [6,7] solved a vibration problem of the thin-walled composite Timoshenko beam with the bending-torsion coupling under axial load using the differential transform method. The governing differential equations of motion were derived. The eigenvalue problem was discussed. In paper [8], Librescu et al. studied the dynamic response of the thin-walled composite beams with embedded piezoceramic layers. The analytical model of the smart system with mechanical and electrical coupling was considered. Ren et al. [9] discussed the dynamic behavior of a rotating composite beam with shape memory alloy. The Euler-Bernoulli beam theory was adopted. Free vibrations of the system were studied. Avramov et al. [10] discussed the dynamic behavior of the rotating Euler-Bernoulli isotropic beams. The study of the flexural-flexural-torsional vibrations was presented.

Awrejcewicz et al. [11] studied theoretically isotropic but geometrically nonlinear beam using Euler-Bernoulli model and finite differences and finite elements method. They indicate conditions to transfer dynamic response of the structure from periodic to quasi-periodic and chaotic motion. However, for beam made from anisotropic material authors apply Timoshenko theory [12]. They discovered that the beams modelled on the basis of the modified couple stress theory are more stiff versus the beams modelled using the classical theory of continuum. They compared a few methods of Lyapunov exponents computation: Wolf algorithm, Rosenstein, Kantz and neural networks.

The dynamic response of the rotating thin walled composite Timoshenko beams with macro fiber composite elements were considered by Choi et al. [13]. Latalski et al. [14] studied the coupled flexural-flexural vibrations of a rotating composite beam. The transversal and lateral bending modal coupling was discussed. The authors used macro fiber composite piezoelectric actuators to control the system. In paper [15] the authors discussed the mathematical model of rotating rigid hub with flexible composite thin-walled beam. The rotary inertia, hub mass moment of inertia, material anisotropy and transverse shear were considered. Therefore, it is shown that the hub inertia has significant impact on systems dynamics. Georgiades et al. [16] studied the rotating composite Timoshenko box-beam. They demonstrated that both the variable rotating speed and nonzero pitch angle need to be considered in modelling of rotating beams. Latalski [17] presented theoretical model of rotating thin-walled composite beam with surface bonded piezoelectric elements. It is shown that electromechanical equations of motion introduces additional stiffness-type couplings between individual degrees of freedom of the hub-beam system. 
The numerical model of the rotating beam was investigated in paper [18]. The authors discussed the geometrically nonlinear vibrations of rectangular cross section beams based on Bernoulii-Euler and Timoshenko theory. The bendingtorsion coupling was studied by finite element method.

Teter et al. [19] presented numerical modal analysis of the rotor with three thin-walled composite blades. The natural frequency and the corresponding shape modes were investigated. Mitura et al. [20] considered dynamic behaviour of the rotor with three active composite blades. The influence of the hub's angular velocity and/or piezoelectric effect on the blades' dynamics in numerical and experimental studies were determined.

In the presented paper, a numerical and experimental modal analysis of a thin-walled composite structures is presented. The circumferentially asymmetric stiffness (i.e., CAS) and circumferentially uniform stiffness (i.e., CUS) beams were considered. In both analyzed cases, the layer-up configurations of the laminate were chosen to get a vibration modes coupling effects. The first and the second mode in flexible and stiff directions as well as torsion modes, were studied. The most interesting modes for CAS beam was the first flapwise bending with torsion coupling mode (i.e. F-T coupling effect). As for the CUS beam, the first mode with bending in two opposite directions: lateral and transversal (i.e., F-C coupling effect) is the most interesting. To verify the vibration modes coupling effects observed for the CAS and CUS beams, many numerical tests for different layer-up configurations of the laminate were performed. Next, the numerical solutions were experimentally validated.

\section{Case studies}

Thin-walled, laminated cantilever box-beams were tested (Fig. 1a). Two different layer-up configurations of the laminate cases were examined. The first one was a beam with circumferentially asymmetric stiffness (i.e., CAS beam - Fig. 1b). This structure is characterized by flapwise bending-torsion vibrations coupling effect (i.e., F-T coupling effect) and chordwise bending-extension vibrations coupling effect (i.e, C-E coupling effect). The second one was a beam with circumferentially uniform stiffness (i.e., CUS beam - Fig. 1c), where a flapwise-chordwise bending vibrations coupling effect (i.e., F-C coupling effect) and torsion-extension vibrations coupling effect (i.e., T-E coupling effect) were observed.

The dimensions of the cantilever box-beam were: length $-900 \mathrm{~mm}$, width $80 \mathrm{~mm}$ and height $-20 \mathrm{~mm}$, respectively. A thickness of each wall was equal to $0.74 \mathrm{~mm}$.

All beams were made of thirteen carbon-epoxy unidirectional layers. Their mechanical properties are listed in Table 1.

The tested beams had $\left[90_{2} / \theta_{4} / 90 / \theta_{4} / 90_{2}\right]_{\mathrm{T}}$ layers configuration, where angle of fibre orientation (denoted as, $\theta$ ) can be changed in range from $0^{\circ}$ to $90^{\circ}$. 


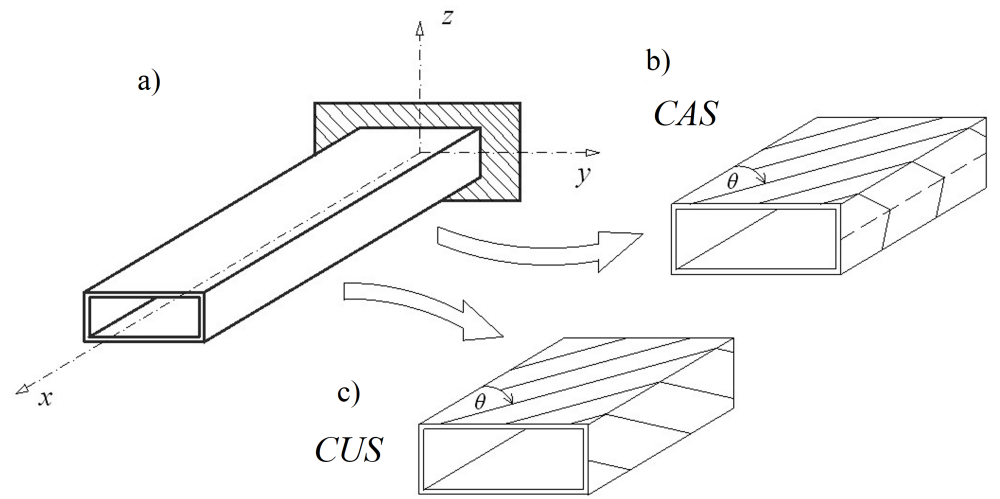

Fig. 1. Scheme of the laminated CAS and CUS box-beams

Table 1.

The mechanical properties of the carbon-epoxy unidirectional laminate

\begin{tabular}{|c|c|c|c|c|}
\hline $\begin{array}{c}\text { Longitudinal } \\
\text { Young's } \\
\text { modulus }\end{array}$ & $\begin{array}{c}\text { Transverse } \\
\text { Young's } \\
\text { modulus }\end{array}$ & $\begin{array}{c}\text { Shear } \\
\text { modulus }\end{array}$ & $\begin{array}{c}\text { Poisson's } \\
\text { ratio }\end{array}$ & Density \\
\hline $143.2 \mathrm{GPa}$ & $3.1 \mathrm{GPa}$ & $3.38 \mathrm{GPa}$ & 0.35 & $1442 \mathrm{~kg} / \mathrm{m}^{3}$ \\
\hline
\end{tabular}

\section{FE model of the thin-walled box-beams}

The numerical model of the CAS and CUS beams with an aluminium grip was created using the finite element method. The mechanical properties of Aluminium are shown in Table 2.

Table 2 .

Mechanical properties of Aluminium

\begin{tabular}{|c|c|c|c|}
\hline $\begin{array}{c}\text { Young's } \\
\text { modulus }\end{array}$ & $\begin{array}{c}\text { Shear } \\
\text { modulus }\end{array}$ & $\begin{array}{c}\text { Poisson's } \\
\text { ratio }\end{array}$ & Density \\
\hline $63 \mathrm{GPa}$ & $24.2 \mathrm{GPa}$ & 0.30 & $7600 \mathrm{~kg} / \mathrm{m}^{3}$ \\
\hline
\end{tabular}

The numerical simulations were performed using the Abaqus software package. The linear FE-model of the thin-walled structure was built using the S8R shell elements [21]. The Layup-Ply technique was used to define configurations of the laminate layers. The numerical, linear model of the grip was built using the solid elements (C3D20R) [21]. All parts of the system were bonded to one another. In the Abaqus system, it was realized by defining interactions as "TIE". The mechanical boundary conditions of the FE model were defined as: all nodes were blocked for one end of the beam, while the second end of the beam was free. In Fig. 2, a FE model of the analyzed beams was presented. The eigenvalue problem was solved using the Lanczos method. The natural frequencies and eigenmodes of free vibrations were determined. 


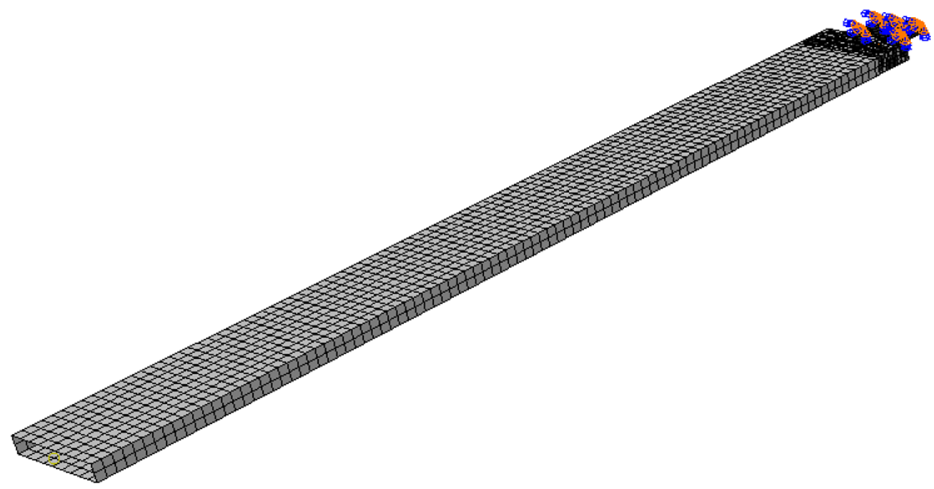

Fig. 2. The numerical model of the box-beam

\section{Validation of the FE model}

The numerical model was verified by experimental tests. Firstly, the test stand of the beam with grip were built and installed at the Lublin University of Technology in the Structures Dynamics Laboratory (Fig. 3).

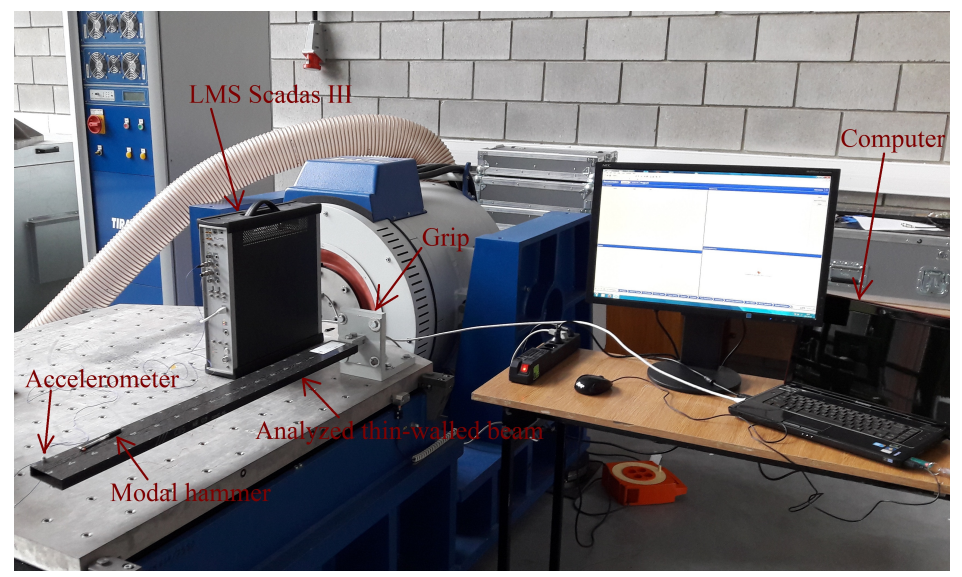

Fig. 3. Test stand with the thin-walled box-beam

Secondly, the modal analysis of the CAS and CUS box-beams with a grip were performed, when an angle of layer orientation (denoted, as $\theta$ ) was $15^{\circ}$. The study was performed using the LMS Scadas III and PQA-2 acquisition card. A sensor (accelerometer) was located near the free end of the beam, the excitation was generated using modal hammer to points of the structure deployed in three lines (i.e., right, central and left ones) along the beam axis. For the right and left lines, the lateral and transversal deflections were available, while only transversal deflections was available for the central line. Two external lines made it possible 
allowed to detect global behaviour of the box-beam, while the middle line provide information about modes, when the upper surface of the beam behave like a plate. The numerical and experimental results are presented in Table 3. The first and second bending modes in flexible and stiff directions were denoted as modes 1-4, respectively. The first and second torsion modes were denoted as modes 5-6. The relative difference of the natural frequencies (Eq. 1) was less than $9 \%$ for bending modes, while for the torsion modes, the error was higher and did not exceed $22 \%$. One of the most interesting modes for the CAS beam was the mode 1, in which the flapwise bending-torsion vibrations coupling effect occured (i.e., F-T effect Fig. 4a). As for the second case, the mode 3 with the chordwise-flapwise bending vibrations coupling effect (i.e. C-F effect - Fig. 4i) was the most impressive.

$$
\Delta R=\frac{\operatorname{Exp}-F E M}{\operatorname{Exp}} 100 \%
$$

Table 3.

Natural frequencies in $\mathrm{Hz}$ and their percentage change in \% (Eq. 1)

\begin{tabular}{|c|r|r|r|r|r|r|}
\hline \multirow{2}{*}{ Modes } & \multicolumn{2}{|c|}{ CAS beam } & \multicolumn{1}{c|}{$\Delta R$} & \multicolumn{2}{c|}{ CUS beam } & $\Delta R$ \\
\cline { 2 - 7 } & FEM & $\begin{array}{c}\text { Experimental } \\
\text { value }\end{array}$ & \multicolumn{1}{c}{$[\%]$} & FEM & $\begin{array}{c}\text { Experimental } \\
\text { value }\end{array}$ & {$[\%]$} \\
\hline 1 & 31.11 & 33.85 & 8.09 & 30.91 & 31.50 & 1.85 \\
\hline 2 & 176.59 & 183.32 & 3.67 & 183.30 & 184.16 & 0.46 \\
\hline 3 & 91.47 & 92.07 & 0.66 & 89.90 & 85.66 & -4.95 \\
\hline 4 & 508.57 & 515.39 & 1.32 & 609.71 & - & - \\
\hline 5 & 329.01 & 296.88 & -10.82 & 238.93 & 241.55 & 1.08 \\
\hline 6 & 530.41 & 437.81 & -21.15 & 497.25 & 430.47 & -15.51 \\
\hline
\end{tabular}

Next, the vertical and horizontal displacements of the points at left $(\mathrm{L})$ and right (R) top edges of the beams were observed. The normalized displacements in $Z$ and $Y$ directions (denoted as, $U z$ and $U y$ respectively) obtained from numerical simulations were compared with the experimental findings (Fig. 5). The experimental displacements in the $Y$ direction of the CAS beam slightly differ from the numerical results. This situation may be that there are some difficulties during experimental research (it is not possible to perfectly hit at the same point). The physical beam, from a technological point of view (orientation of the individual layers may slightly diverge from the adopted directions), may differ from the numerical model. As a result of the vibrations coupling effect, the left and right lines can have different shapes. Other findings showed a very good agreement. A flapwise bending-torsion vibrations coupling effect and a second flapwise bending with the first chordwise bending vibrations coupling effect were observed at CAS and CUS beam, respectively. 

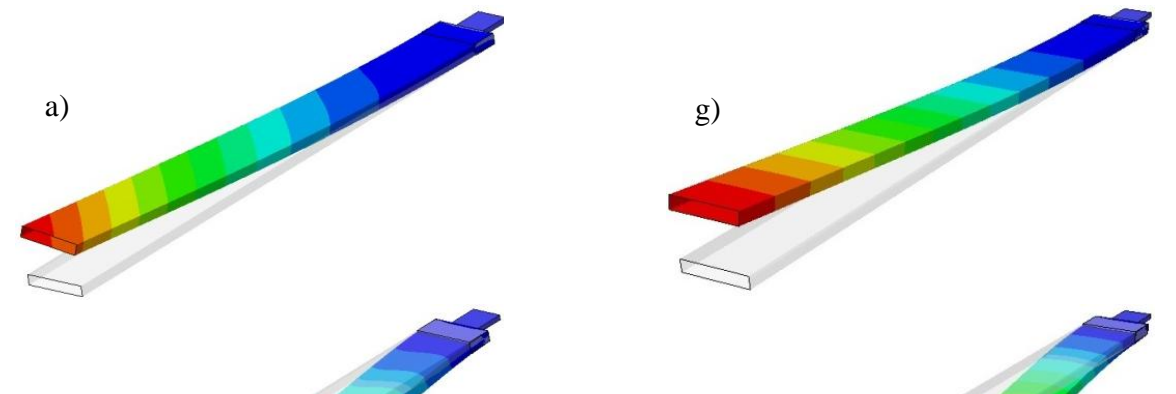

b)
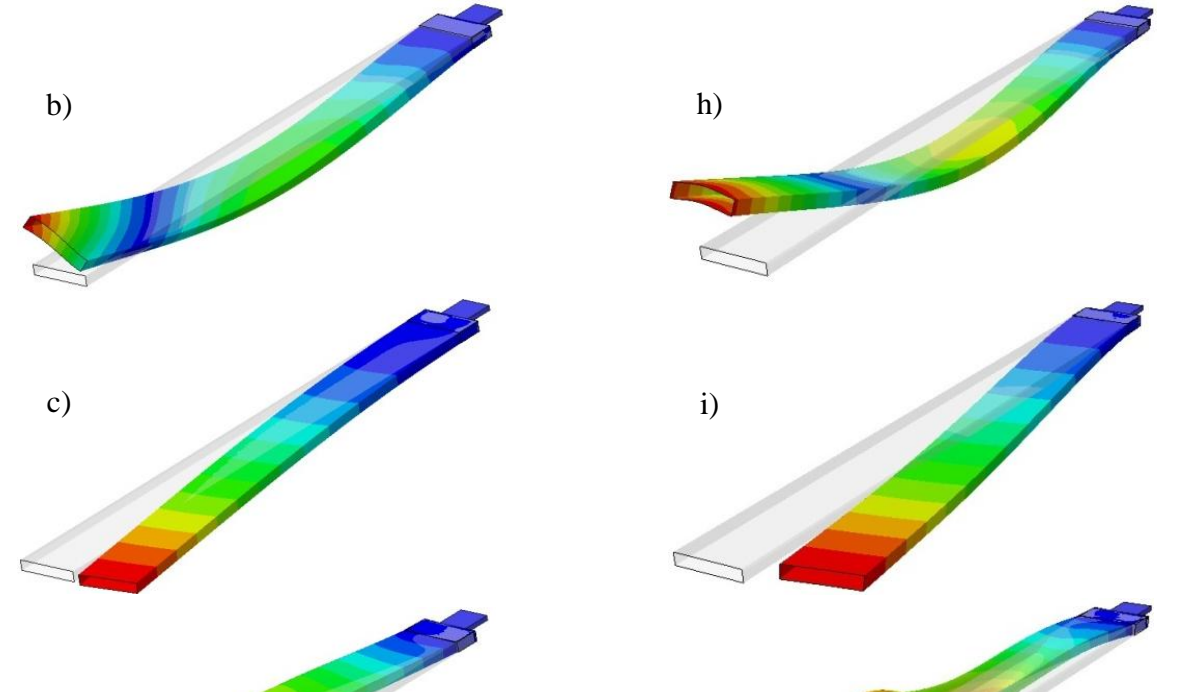

d)
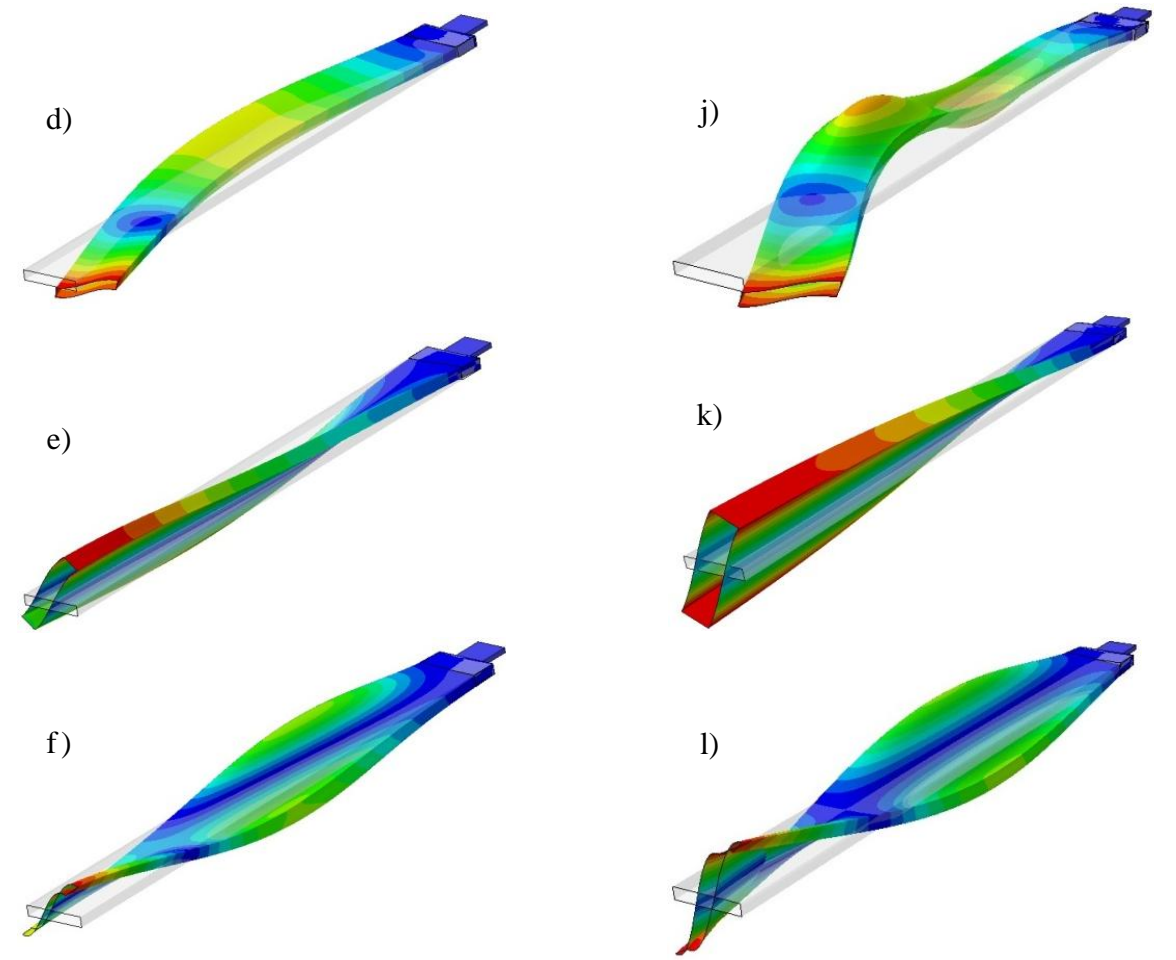

Fig. 4. The eigenmodes of the beams: a-f) CAS; g-1) CUS 

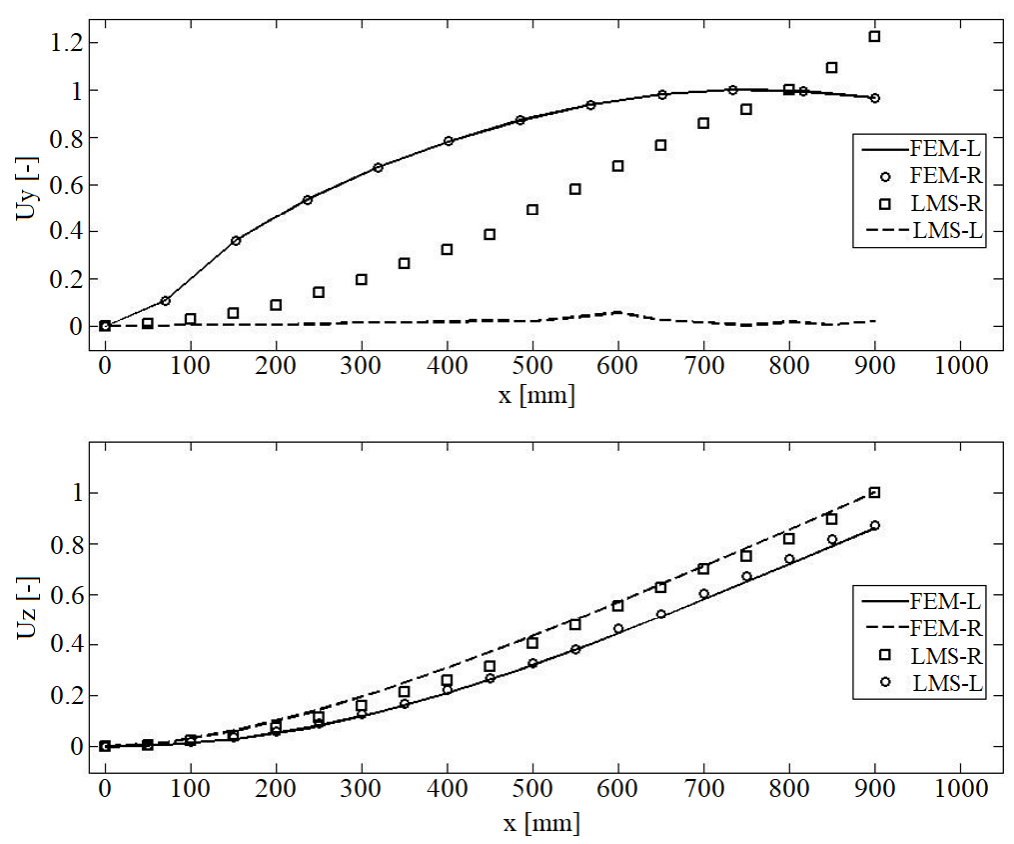

(a) CAS beam
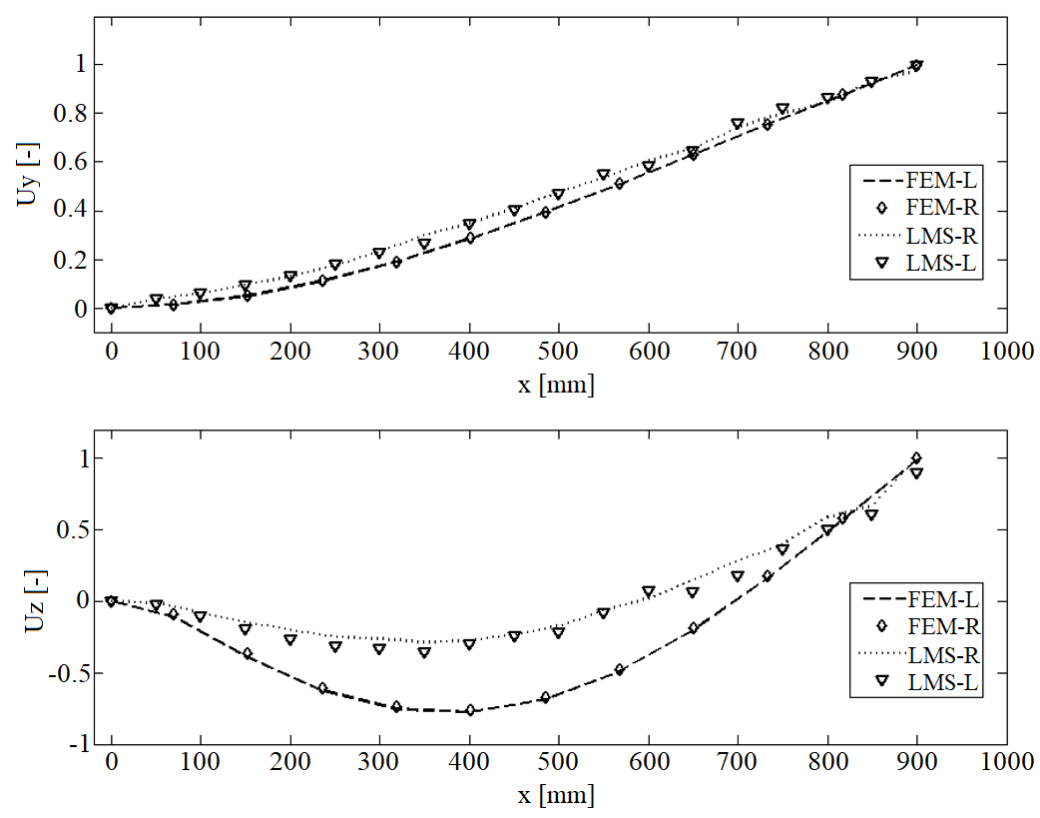

(b) CUS beam

Fig. 5. Comparison of the numerical and experimental results for CAS beam and CUS beam 


\section{Numerical analysis of the coupling effects}

To verify of the effects observed for the CAS and CUS beams, the numerical simulations were performed. The eigenvalue problem was solved for all beams, when an angle of layer orientation (denoted, as $\theta$ ) specified with step $15^{\circ}$ in the range from $15^{\circ}$ to $75^{\circ}$. The specimens were denoted as $\mathrm{C} \theta$ in both cases. The natural frequencies of the analyzed beams are presented in Tables 4 and 5 .

Table 4.

Natural frequencies in $\mathrm{Hz}$ of the CAS beam

\begin{tabular}{|l|r|r|r|r|r|}
\hline Modes & \multicolumn{1}{|c|}{ C15 } & \multicolumn{1}{c|}{ C30 } & \multicolumn{1}{c|}{ C45 } & \multicolumn{1}{c|}{ C60 } & \multicolumn{1}{c|}{ C75 } \\
\hline First F-T & 31.11 & 19.76 & 14.44 & 11.79 & 10.51 \\
\hline Second F-T & 176.59 & 120.63 & 89.26 & 73.03 & 64.96 \\
\hline First C-E & 91.47 & 58.77 & 42.77 & 34.70 & 30.81 \\
\hline Second C-E & 508.57 & 348.38 & 259.33 & 211.93 & 187.95 \\
\hline First T-F & 329.01 & 404.55 & 413.16 & 386.48 & 292.06 \\
\hline Second T-F & 530.41 & 559.69 & 570.67 & 592.34 & 570.40 \\
\hline
\end{tabular}

F-T - flapwise bending with torsion, C-E - chordwise bending with extension, T-F - torsion with flapwise bending

Table 5 .

Value of the natural frequencies in $\mathrm{Hz}$ of the CUS beam

\begin{tabular}{|l|r|r|r|r|r|}
\hline Modes & \multicolumn{1}{c|}{ C15 } & \multicolumn{1}{c|}{ C30 } & \multicolumn{1}{c|}{ C45 } & \multicolumn{1}{c|}{ C60 } & \multicolumn{1}{c|}{ C75 } \\
\hline First F-C & 30.91 & 19.80 & 14.54 & 11.90 & 10.63 \\
\hline Second F-C & 183.30 & 122.40 & 90.28 & 73.84 & 65.68 \\
\hline First C-F & 89.90 & 58.33 & 42.82 & 34.94 & 31.13 \\
\hline Second C-F & 609.71 & 411.34 & 288.42 & 224.68 & 192.40 \\
\hline First T-E & 238.93 & 250.38 & 270.39 & 292.49 & 281.20 \\
\hline Second T-E & 497.25 & 502.98 & 528.71 & 563.70 & 568.56 \\
\hline
\end{tabular}

F-C - flapwise with chordwise bending, C-F - chordwise with flapwise bending, T-E - torsion with extension

For the CAS beam the first F-T mode detailed analysis were conducted. The displacement of the points at the right and left edges of the beam in two direction are shown in Fig. 6. In flexible direction the $\mathrm{C} 15$ beam was the stiffest one, but the most susceptible was the $\mathrm{C} 75$ beam. The situation was opposite in the stiff direction. The flapwise bending effect was more noticeable than the torsion effect. It was a dominant effect. The torsion effect increased, when the fibres were in the longitudinal direction.

The first C-F mode of the CUS beam was discussed. The vertical and horizontal displacements of the measuring points at right and left edges of the free box-beam's end were presented in Fig. 7. In this case, the first chordwise bending mode with the second flapwise bending mode were observed. The $\mathrm{C} 75$ beam was the stiffest one. 

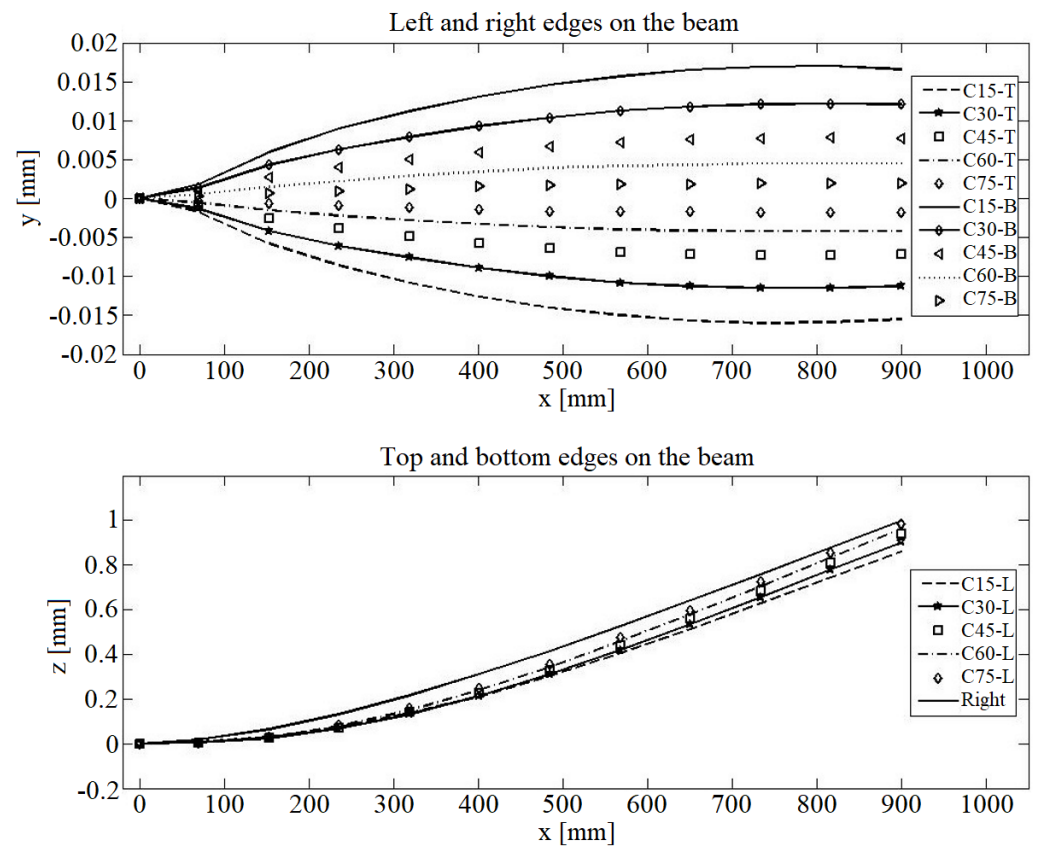

Fig. 6. Displacements of the measuring points versus length of the CAS beam for all cases
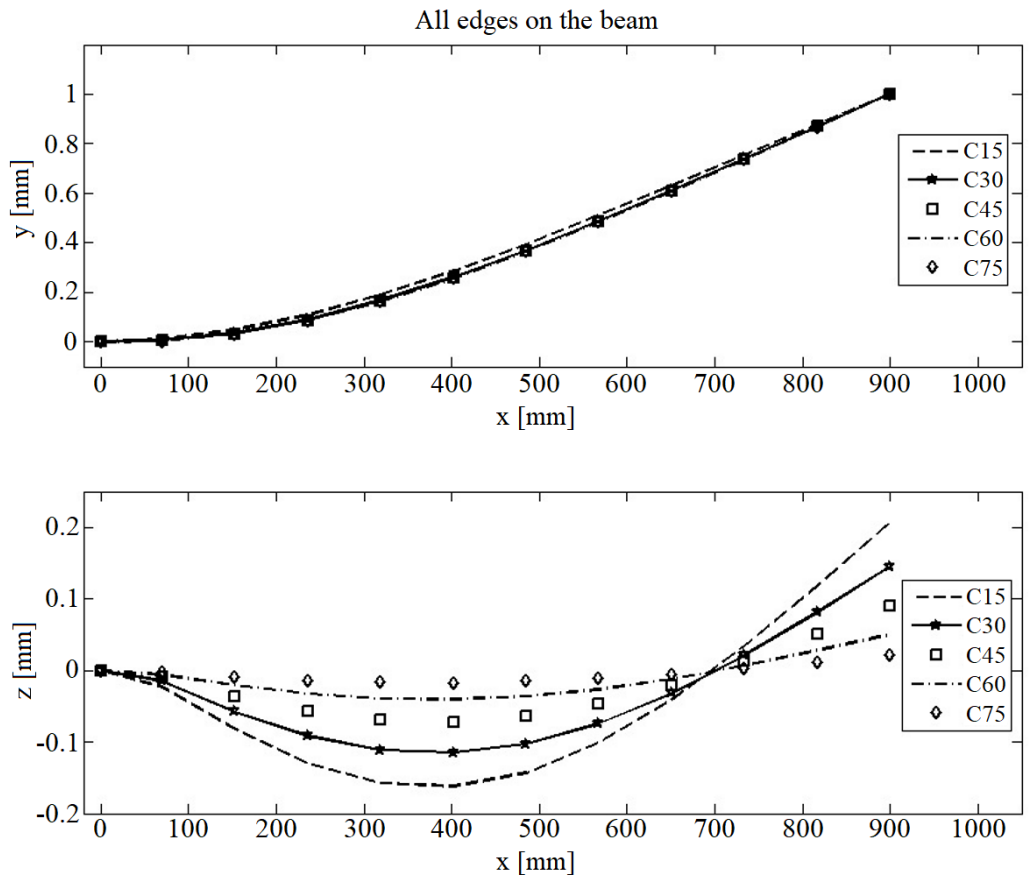

Fig. 7. Displacements of the measuring points versus length of the CUS beam for all cases 
The deflections of all beam edges were identical for both directions. The dominant effect was a bending in stiff direction. A change in the orientation of the laminate fibers reduces the bending effect in the flexible direction. The maximum difference between the $\mathrm{C} 15$ and $\mathrm{C} 75$ beams were $8 \%$ in stiff and $89 \%$ in flexible directions, respectively.

At the next step, the static analysis of the presented beams under constant pressure maintained at $0.001 \mathrm{MPa}$ was discussed. In CAS and CUS beams, the constant load was applied to one beam surface in $Z$ and $Y$ directions, respectively. Torsion angles of the CAS cross-sections, perpendicular to the axis of the deformed beam were determined. The results obtained for both cases are presented in Fig. 8. The highest value of torsion angle of the cross-section was achieved by the $\mathrm{C} 45$ beam. The $\mathrm{C} 75$ beam was the most flexible one. The twisting effect of the cross-section did not occur in the CUS beam. However, the lateral and transversal displacements of the cross-section strongly depend on the fibre orientation. The highest effect was observed for the $\mathrm{C} 75$ beam in transversal direction. The $\mathrm{C} 45$ beam was the most susceptible to deflection in lateral direction.

\section{Conclusions}

In presented paper, a numerical and experimental modal analysis of the thinwalled cantilever composite structures were discussed. The circumferentially asymmetric stiffness beam and the circumferentially uniform stiffness beam were considered. All simulations were performed by the finite element methods. The natural frequencies and corresponding shape modes were determined. To solve the eigenvalue problem, the Lanczos method was applied. The experimental modal analysis of the analyzed structure were performed using the LMS Scadas III with a modal hammer and acceleration sensor. The numerical results were compared with the experimental findings. A very good agreement was achieved except for the displacement in stiff direction of the CAS beam.

The most interesting mode observed for the CAS beam was the first mode with F-T coupling effect. As regards the CUS beam, the first mode with C-F coupling effect was the most impressive. In order to verify the effects observed for both beams, the numerical specific tests were performed. The $\mathrm{C} 15$ beam was the stiffest one in flexible direction, while the $\mathrm{C} 75$ was the most susceptible. The trend is opposite in stiff direction. In this case, the flapwise bending effect was dominant. The torsion effect increased, when the fibres were in the longitudinal direction. The first bending mode in stiff direction and the second bending mode in flexible direction can be observed for the CUS beam. The CUS beam was the stiffest for the $\mathrm{C} 75$ beam. The dominant effect was a chordwise bending. Modification of the laminate fibers orientation can be used to control of the bending effect in the flexible direction.

The influence of the fiber orientation in laminate on torsion stiffeners of the CAS and CUS beams was discussed. The C45 beam had the highest value of 


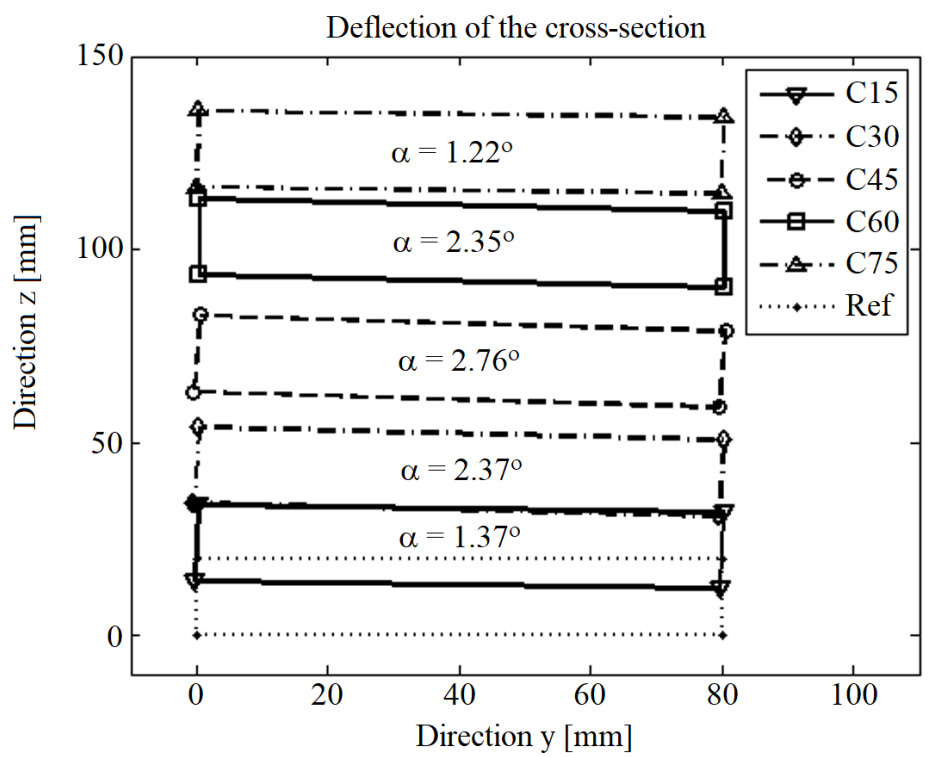

(a)
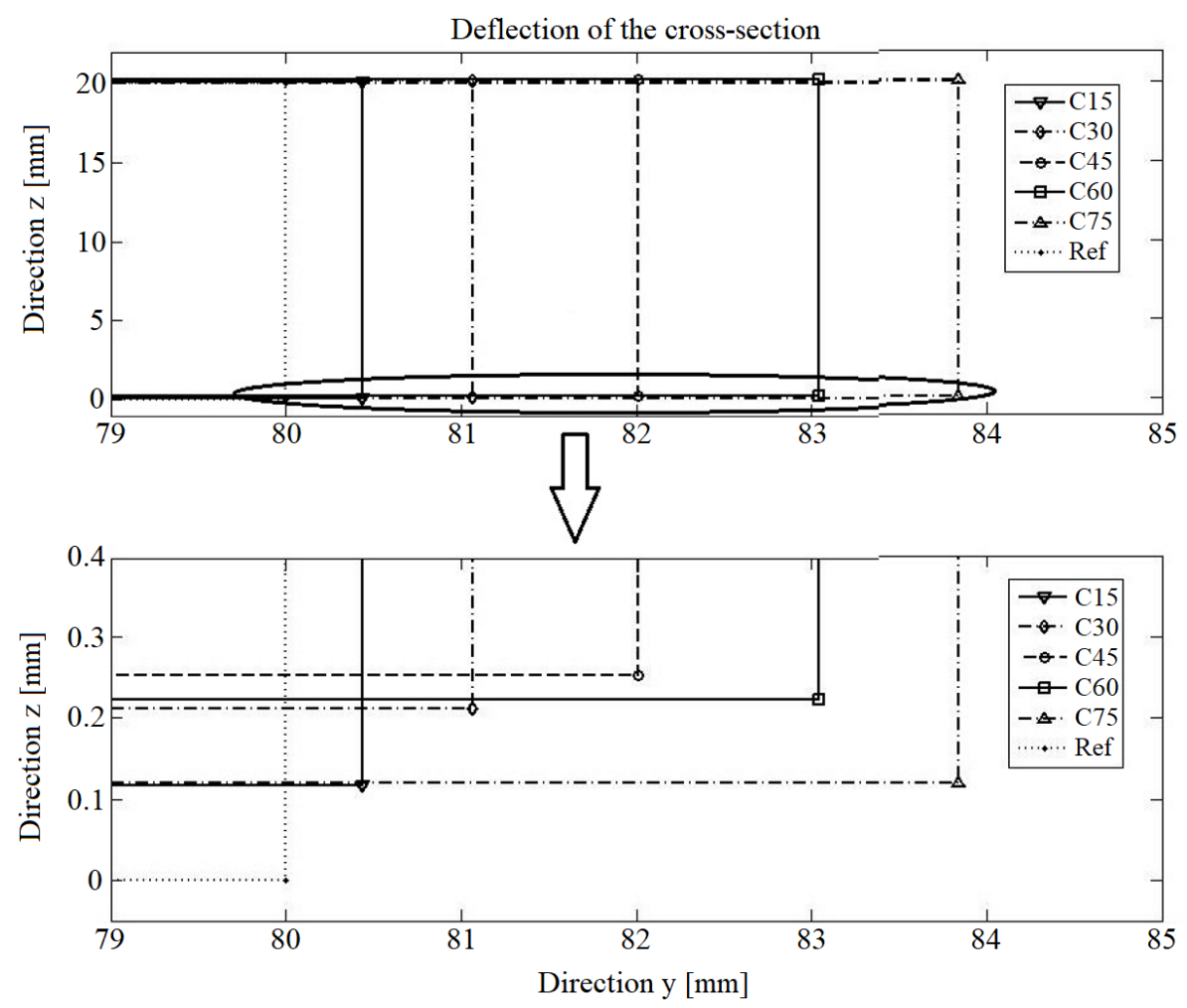

(b)

Fig. 8. Behaviour of the cross-sections: a) CAS beam , b) CUS beam 
torsion angle of the cross-section under constant load. The lateral and transversal displacements of the cross-section for the CUS beam strongly depend on the fibre orientation. The CAS and CUS beams were the stiffest ones, when the $\theta$ angle was equal to $15^{\circ}$.

The numerical simulations and the experimental studies performed in this paper will be used for a further research on the dynamics of the thin-walled composite structures.

\section{Acknowledgements}

This research was financially supported by the Polish National Science Centre under Research Grant No. DEC-2012/07/B/ST8/03931.

Manuscript received by Editorial Board, June 17, 2017;

final version, October 16, 2017.

\section{References}

[1] O. Song and L. Librescu. Structural modeling and free vibration analysis of rotating composite thin-walled beams. Journal of the American Helicopter Society, 42(4):358-369, 1997. doi: 10.4050/JAHS.42.358.

[2] O. Song and L. Librescu. Free vibration of anisotropic composite thin-walled beams of closed cross-section contour. Journal of Sound and Vibration, 167(1):129-147, 1993. doi: 10.1006/jsvi.1993.1325.

[3] S.-Y. Oh, O. Song, and L. Librescu. Effects of pretwist and presetting on coupled bending vibrations of rotating thin-walled composite beams. International Journal of Solids and Structures, 40(5):1203-1224, 2003. doi: 10.1016/S0020-7683(02)00605-4.

[4] O. Song and L. Librescu. Bending vibration of cantilevered thin-walled beams subjected to time-dependent external excitations. The Journal of the Acoustical Society of America, 98(1):313-319, 1995. doi: 10.1121/1.414358.

[5] L. Jun and J. Xianding. Response of flexure-torsion coupled composite thin-walled beams with closed cross-sections to random loads. Mechanics Research Communications, 32(1):25-41, 2005. doi: 10.1016/j.mechrescom.2004.03.012.

[6] M.O. Kaya. Free vibration analysis of a rotating Timoshenko beam by differential transform method. Aircraft Engineering and Aerospace Technology, 78(3):194-203, 2006. doi: $10.1108 / 17488840610663657$.

[7] M.O. Kaya and O.O. Ozgumus. Flexural-torsional-coupled vibration analysis of axially loaded closed-section composite Timoshenko beam by using DTM. Journal of Sound and Vibration, 306(3):495-506, 2007. doi: 10.1016/j.jsv.2007.05.049.

[8] L. Librescu and O. Song. Thin-Walled Composite Beams: Theory and Application. Solid Mechanics and Its Applications. Springer Science \& Business Media, 2005.

[9] Y. Ren, S. Yang, and X. Du. Modeling and free vibration behavior of rotating composite thinwalled closed-section beams with SMA fibers. Chinese Journal of Mechanical Engineering, 25(5):1029-1043, 2012. doi: 10.3901/CJME.2012.05.1029.

[10] K.V. Avramov, C. Pierre, and N. Shyriaieva. Flexural-flexural-torsional nonlinear vibrations of pre-twisted rotating beams with asymmetric cross-sections. Journal of vibration and Control, 13(4):329-364, 2007. doi: 10.1177/1077546307073675. 
[11] S.-C. Choi, J.S-. Park, and J.-H. Kim. Active damping of rotating composite thin-walled beams using MFC actuators and PVDF sensors. Composite Structures, 76(4):362-374, 2006. doi: 10.1016/j.compstruct.2005.05.010.

[12] J. Latalski, M. Bocheński, and J. Warmiński. Control of bending-bending coupled vibrations of a rotating thin-walled composite beam. Archives of Acoustics, 39(4):605-613, 2014. doi: 10.2478/aoa-2014-0065.

[13] J. Latalski, J. Warminski, and G. Rega. Bending-twisting vibrations of a rotating hub-thinwalled composite beam system. Mathematics and Mechanics of Solids, 22(6):1303-1325, 2017. doi: $10.1177 / 1081286516629768$.

[14] F. Georgiades, J. Latalski, and J. Warminski. Equations of motion of rotating composite beam with a nonconstant rotation speed and an arbitrary preset angle. Meccanica, 49(8):1833-1858, 2014. doi: 10.1007/s11012-014-9926-9.

[15] J. Latalski. Modeling of a rotating active thin-walled composite beam system subjected to high electric fields. In Konstantin Naumenko and Marcus Aßmus, editors, Advanced Methods of Continuum Mechanics for Materials and Structures, chapter 24, pages 435-455. Springer, 2016.

[16] L.T. Tenek and J. Argyris. Finite Element Analysis for Composite Structures, volume 59 of Solid Mechanics and Its Applications. Springer Science \& Business Media, 2013.

[17] F.L. Matthews, G.A.O. Davies, D. Hitchings, and C. Soutis. Finite Element Modelling of Composite Materials and Structures. Elsevier Science, 2000.

[18] S. Stoykov and P. Ribeiro. Nonlinear forced vibrations and static deformations of 3D beams with rectangular cross section: the influence of warping, shear deformation and longitudinal displacements. International Journal of Mechanical Sciences, 52(11):1505-1521, 2010. doi: 10.1016/j.jimecsci.2010.06.011.

[19] A. Teter and J. Gawryluk. Experimental modal analysis of a rotor with active composite blades. Composite Structures, 153:451-467, 2016. doi: 10.1016/j.compstruct.2016.06.013.

[20] A. Mitura, J. Gawryluk, and A. Teret. Numerical and experimental studies on the rotating rotor with three active composite blades. Eksploatacja i Niezawodnosc-Maintenance and Reliability, 19(4):571-579, 2017. doi: 10.17531/ein.2017.4.11.

[21] Abacus: documentation 6.14. 